\title{
Numerical Study on Thermal Effects of Cold and High-albedo Surfaces Covered with Snow in Outdoor Environments
}

\author{
Akashi Mochida ${ }^{1}$, Yoshihide Tominaga ${ }^{2}$, Hiroshi Yoshino ${ }^{3}$ \\ Kiyoshi Sasaki ${ }^{4}$ and Makiko Ohba ${ }^{5}$

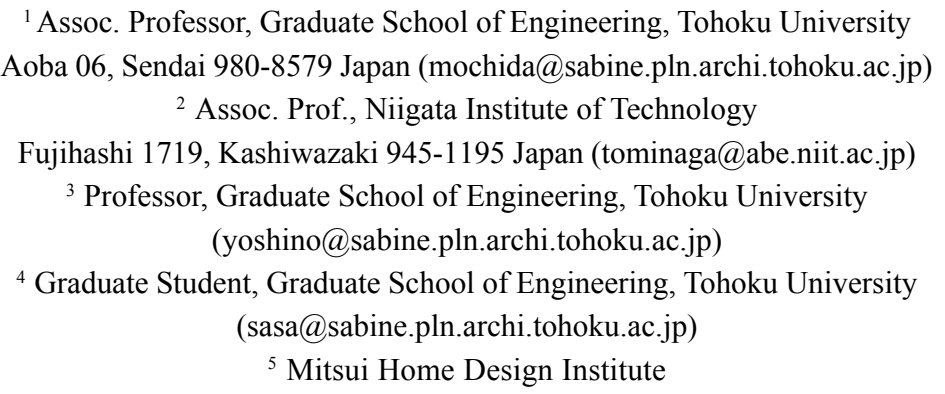 \\ 23-2 Sakamachi, Sinjuku-ku, Tokyo 160-0002 Japan
}

\begin{abstract}
In this study, a numerical method for predicting the radiative and convective heat transports around building blocks in a snowy region is developed. A field measurement is also carried out to clarify the effects of cold and high-albedo surfaces covered with snow. Although the surface temperature of the ground covered with snow was lower than that without snow, MRT and SET* above the snow surface were predicted to be higher than those without snow. This reflects the large effect of an increased albedo of the ground surface due to snow.
\end{abstract}

Keywords: Snow; High-albedo; Outdoor thermal environment; Radiation; CFD

\section{Introduction}

Accumulations of snow greatly change the physical properties of the urban surface. The cold and highalbedo urban surfaces covered with snow strongly affect the heat transfer mechanism within the outdoor space as illustrated in Fig. 1. The effects of snow at ground surface are an important topic in the field of meteorology and many investigations have been carried out over the years, e.g. Kondo and Yamazaki (1986, 1987, 1990). However, those works were merely placed on the heat energy balance at the surface of the ground. Studies of the heat transfer above the snow at pedestrian level, involving air movement, are lacking. In addition, research studies on the radiative heat transfer between the ground surface covered with snow and building walls, and its effects on convective heat transfer due to the airflow movement around buildings are also limited at present.

In this study, a numerical method is developed for predicting radiative and convective heat transports in an

Contact author: Akashi Mochida, Graduate School of Eng., Tohoku Univ., Aoba 06, Sendai 980-8579 Japan

Tel: +81-22-217-7884, Fax: +81-22-217-7886

e-mail:mochida@sabine.pln.archi.tohoku.ac.jp

(Received September 7, 2001; accepted December 20, 2001)

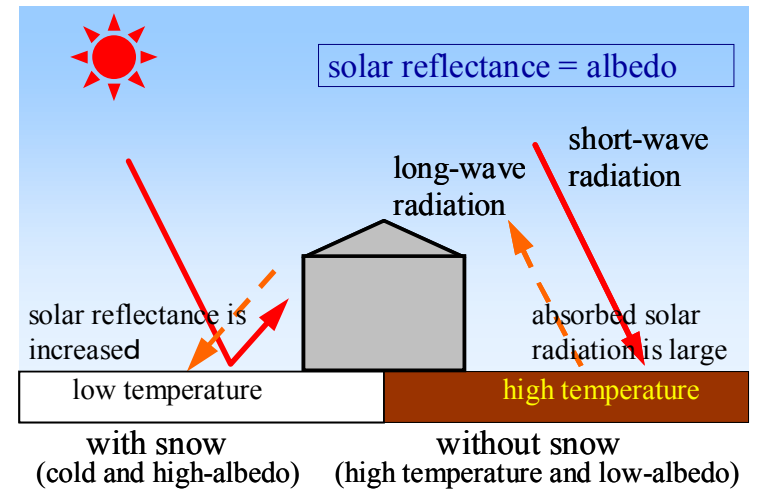

(1) radiation field

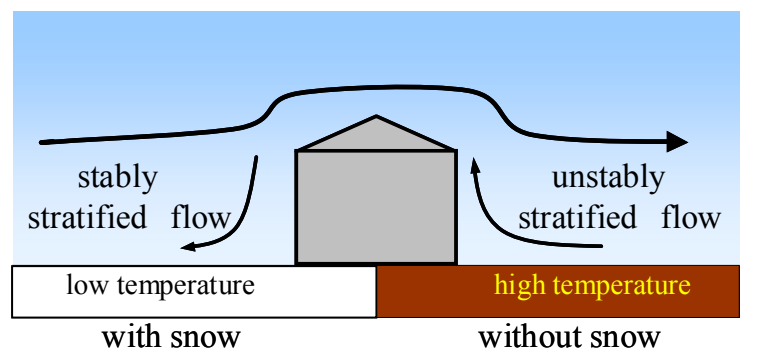

(2) convection field

Fig. 1. Effects of snow on outdoor environment 


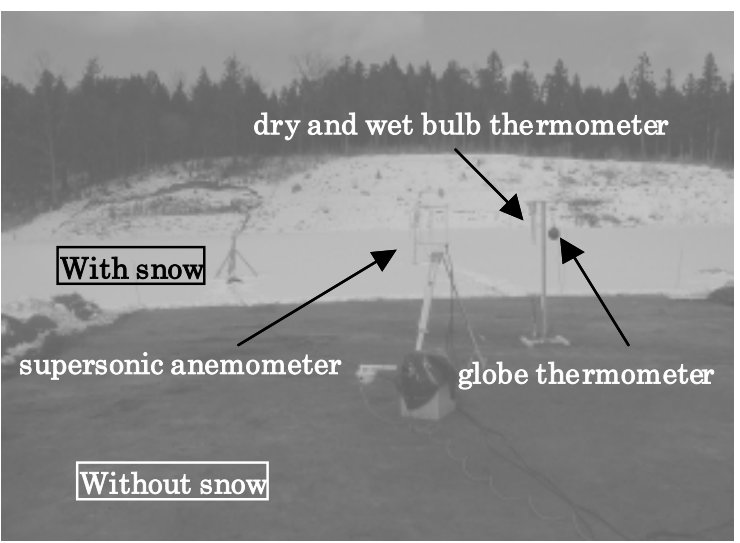

Fig.2. Situation of field measurement

Table 1. Measured quantities

\begin{tabular}{l}
\hline $\begin{array}{l}\text { Global solar radiation }\left(\mathrm{E}_{\mathrm{D}}\right) \\
\text { (direct solar radiation }+ \text { diffuse radiation) }\end{array}$ \\
\hline $\begin{array}{l}\text { Reflected solar radiation }\left(\mathrm{E}_{\mathrm{R}}\right) \\
\text { (from the snow covered surface) }\end{array}$ \\
\hline Wet and dry bulb temperature \\
\hline Globe temperature $\left(\theta_{\text {globe }}\right)$ \\
\hline Ground surface temerature $\left(\theta_{\mathrm{s}}\right)$ \\
\hline Radiation temperature on ground surface \\
\hline Wind direction, wind velocity \\
\hline
\end{tabular}

outdoor space of a snowy region. The effects of the changes in surface parameters, i.e. the decrease of surface temperature and increase of albedo caused by snow, on the outdoor thermal environment are numerically investigated. In the first part of this paper, the results from the field measurement are presented to clarify the basic effects of cold and high-albedo ground surface covered with snow. The accuracy of the radiation computation is confirmed by comparing its result with field measurements. The latter part describes the computations of radiative and convective heat transports around the model of building blocks. Four cases of computations are carried out here in order to examine the effects of the snow surface on the outdoor thermal environment.

\section{Field Measurements}

\subsection{Outlines of the Measurement}

A full-scale field measurement was carried out in a playground at the Niigata Institute of Technology, Niigata Prefecture, Japan, on February 23, 2000. The weather was cloudy, fine at times, and the snow was 8 $\mathrm{cm}$ deep. Fig. 2 shows the configuration of the field measurement. Measurements were taken from two different areas; with snow and without snow. The size of the area without snow was 10 square meters. Table 1 summarizes the measured quantities.

\subsection{Results of the Field Measurement}

Fig.3. shows the global solar radiation ( $E D$, direct radiation + diffuse radiation) and the albedo of ground covered with snow. The maximum of $\mathrm{E}_{\mathrm{D}}$ is about $600 \mathrm{~W} /$ $\mathrm{m}^{2}$ observed at 1:30 p.m. The albedo of ground cov-

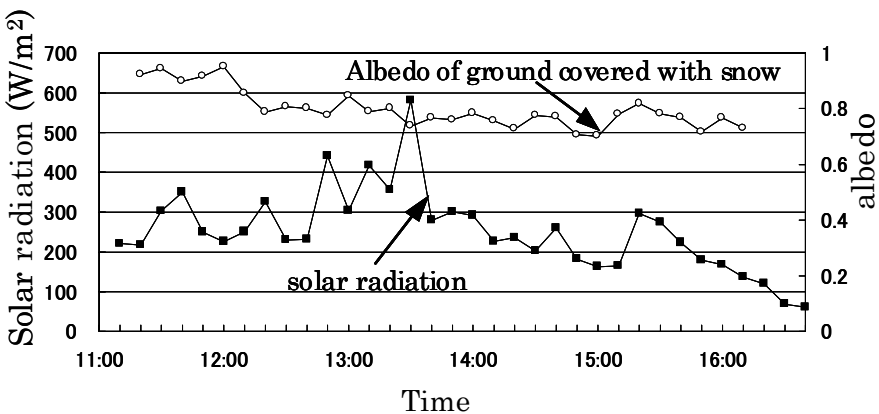

Fig.3. Global solar radiation and albedo of the snow surface

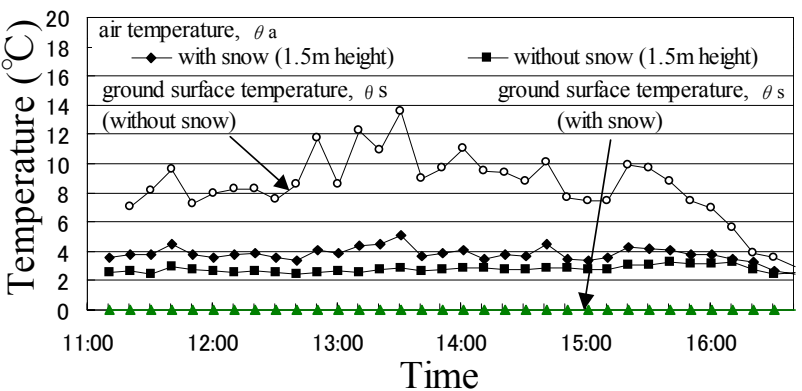

Fig.4. Air temperature and ground surface temperature

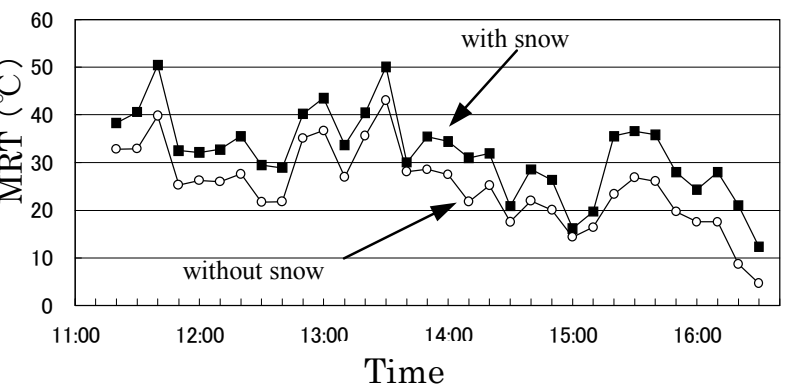

Fig.5. MRT value at $1.5 \mathrm{~m}$ height

Table 2. Comparison of MRT values at 1:30p.m (at $1.5 \mathrm{~m}$ height)

\begin{tabular}{ccc}
\hline & measurement & computation \\
\hline with snow & $50.1^{\circ} \mathrm{C}$ & $48.4^{\circ} \mathrm{C}$ \\
without snow & $43.1^{\circ} \mathrm{C}$ & $38.9^{\circ} \mathrm{C}$ \\
\hline
\end{tabular}

ered with snow is around 0.8 throughout the day.

Fig. 4 illustrates the time variations of air temperatures, $\theta$ a, at the height of $1.5 \mathrm{~m}$, and ground surface temperatures, $\theta$ s. $\theta$ a recorded at $1.5 \mathrm{~m}$ are approximately $3^{\circ} \mathrm{C} \sim 4^{\circ} \mathrm{C}$ throughout the measurement period. $\theta$ s with and without snow are $0^{\circ} \mathrm{C}$ and $3^{\circ} \mathrm{C} \sim 14^{\circ} \mathrm{C}$ respectively.

Variations of Mean Radiative Temperature (MRT) at a height of $1.5 \mathrm{~m}$, calculated based on the measured data, are compared in Fig. 5. MRT value, $\theta \mathrm{r}$, for the ground covered with snow, which is evaluated from the globe temperature (cf. Appendix 1), is found to be higher than that without snow throughout the day. Although the surface temperature of ground covered with snow is lower, MRT above this area is higher than the surface without snow. This is because the albedo of the surface covered with snow is much higher than that without snow. 
Table 3. Computation Conducted for All Test Cases

\begin{tabular}{l|c|c|c}
\hline \multicolumn{1}{c|}{ Case } & Albedo of ground surface & Ground surface temperature $(\theta$ s) & Soil moisture availability \\
\hline case 1 (ground: without snow) & 0.2 & $\begin{array}{c}\text { given from radiation computation } \\
\left(7 \sim 27^{\circ} \mathrm{C}\right)\end{array}$ & 0.15 \\
\hline case 2 & 0.2 & $0 \mathrm{C}$ & 1.0 \\
\hline case 3 & 0.8 & $\begin{array}{c}\text { given from radiation computation } \\
\left(5 \sim 15^{\circ} \mathrm{C}\right)\end{array}$ & 0.15 \\
\hline case 4 (ground: with snow) & 0.8 & $0{ }^{\circ} \mathrm{C}$ & 1.0 \\
\hline
\end{tabular}

Radiation computation based on the Monte-Carlo simulation is carried out to confirm its accuracy by using data at 1:30 p.m. where the solar radiation shows its maximum. The outline of radiation computation for predicting the outdoor thermal environment in a snowy region is summarized in Appendix 2. In this study, the effect of the energy of snowmelt is included in the equation of heat energy balance at the ground surface (cf. eq. (4) in Appendix 2).

Table 2 shows the comparison of MRT values between the results of measurement and computation. As already noted, the MRT value above the snow surface is much higher than that without snow. It can be seen that a fairly good agreement of such tendency is obtained computationally.

The effects of snow on the mechanism of heat transports around buildings are investigated, by using the numerical approach described in Appendix 2, and highlighted in the next section.

\section{Effects of Snow Covered Ground Surface on Radiative and Convective Heat Transports around Buildings \\ 3.1 Outlines of the Computation}

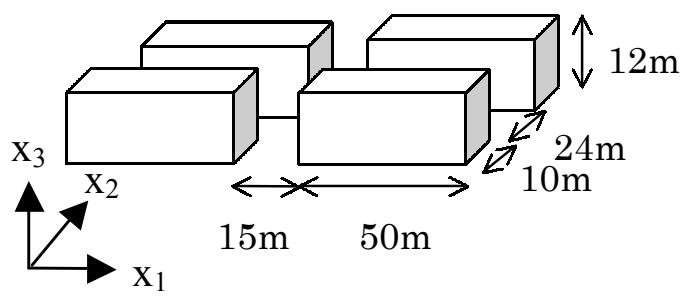

(a) Exterior of buildings

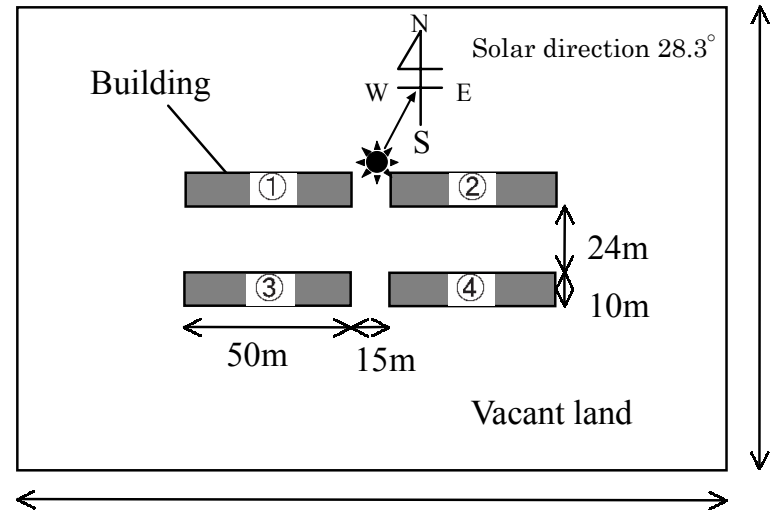

$215 \mathrm{~m}$

(b) Horizontal plan

Fig.6. Computation domain
Table 4. Model for sensible and latent heat fluxes including buoyancy effect

$$
\begin{aligned}
& \text { 1. Sensible heat flux }-\left\langle u_{3}^{\prime} \theta_{a}^{\prime}\right\rangle=\frac{v_{t}}{\sigma_{\theta}} \frac{\partial\left\langle\theta_{a}\right\rangle}{\partial x_{3}}+\frac{k}{\varepsilon} C_{\theta 3} g_{3} \beta\left\langle\theta_{a}^{\prime 2}\right\rangle \\
& \text { 2. Latent heat flux } \quad-\left\langle u_{3}^{\prime} q_{w}^{\prime}\right\rangle=\frac{v_{t}}{\sigma_{w}} \frac{\partial\left\langle q_{w}\right\rangle}{\partial x_{3}}+\frac{k}{\varepsilon} C_{\theta 3} g_{3} \beta\left\langle\theta_{a}^{\prime} q_{w}^{\prime}\right\rangle \\
& g_{3}=-9.8 m / s, C_{\theta 1}=0.25, C_{\theta 3}=0.25, \sigma_{\theta}=0.5, \sigma_{w}=0.5
\end{aligned}
$$

Fig. 6 details the model of building block used for the present study. Four five-story buildings are arranged within the computational flow domain.

Table 3 lists all the test cases for the computation. Cases 1 and 4 consider the ground without snow and with snow covering, respectively. Two different features peculiar to the surface covered with snow, cold and highalbedo, are adopted and investigated in Cases 2 and 3 separately. Case 2 considers only the decrease of longwave radiation from a cold snow surface, while Case 3 examines the effects of increased short-wave radiation caused by the high-albedo of snow. In all cases, the albedo of the building surfaces is set to 0.2 .

The outdoor thermal environments on a sunny day are numerically studied in these computations. The meteorological data of Nagaoka City, Niigata Prefecture, Japan, at 1:30 p.m. on February 23 is used to specify the numerical conditions. The air temperature and relative humidity on average in the past 15 years are 1.4 ${ }^{\circ} \mathrm{C}$ and $70 \%$, respectively. These values are imposed as the boundary conditions. Wind conditions are given based on the mean velocity value and prevailing wind direction in February in Nagaoka city. Wind velocity at $6.5 \mathrm{~m}$ height and wind direction at inflow boundary are set at $1.71 \mathrm{~m} / \mathrm{s}$ and SSW respectively. The vertical profile of mean velocity at the inflow boundary is assumed to obey a $1 / 4$ power law.

A revised $\mathrm{k}-\varepsilon$ model, in which some modifications are added to Launder-Kato type $\mathrm{k}-\varepsilon$ model (Kato and Launder (1993)) by the present authors (Yoshida et al. (2000)), is used to predict convective heat transports around the buildings. This modified LK model is further revised to include the correct buoyancy effects on sensible and latent heat fluxes as shown in Table 4 (Murakami et al. (1999), Yoshida et al. (2000)). Radiative heat transport is computed using the method based on the Monte - Carlo simulation described in Appendix 2.

Spatial distribution of SET* (Standard Effective Temperature) proposed by Gagge et al (1986) is calcu- 
lated in order to assess pedestrian level thermal comfort using the data given from CFD predictions (cf. Appendix 3).

For boundary conditions at the ground surface, the log law expression that incorporates the influence of roughness length $\mathrm{z}_{0}$ is employed. The values of $\mathrm{z}_{0}$ and mean friction velocity $\left\langle\mathrm{u}^{*}\right\rangle$ are set equal to $0.3 \mathrm{~m}$ and $0.22 \mathrm{~m} / \mathrm{s}$ respectively. The boundary conditions at building surfaces are given by the generalized log law proposed by Launder et. al. (1974). The sensible heat fluxes, $\mathrm{Hi}$, at the ground surface and building walls are evaluated by

$$
\mathrm{Hi}=\alpha \mathrm{c}\left(\left\langle\theta_{\text {ap }}\right\rangle-\left\langle\theta_{\mathrm{s}}\right\rangle\right),
$$

where $\alpha$ c: convective heat transfer coefficient

$\left(11.6 \mathrm{~W} / \mathrm{m}^{2}\right.$ in this study),

$\langle\theta$ ap $\rangle:$ mean air temperature at the grid adjacent to the wall,

$\langle\theta$ s $\rangle$ : mean surface temperature.

The computational domain covers $215 \mathrm{~m}$ ( $\mathrm{x}_{1}$, east-west direction $) \times 144 \mathrm{~m}\left(\mathrm{x}_{2}\right.$, north-south direction $) \times 192 \mathrm{~m}$ ( $\mathrm{x}_{3}$, vertical direction). The domain is discretized into $42\left(\mathrm{x}_{1}\right) \times 30\left(\mathrm{x}_{2}\right) \times 14\left(\mathrm{x}_{3}\right)$ grids. The value of mesh interval adjacent to the solid wall is set at $2.0 \mathrm{~m}$. The QUICK scheme is used for the convection terms and the second-order central difference scheme is adopted for other spatial derivatives.

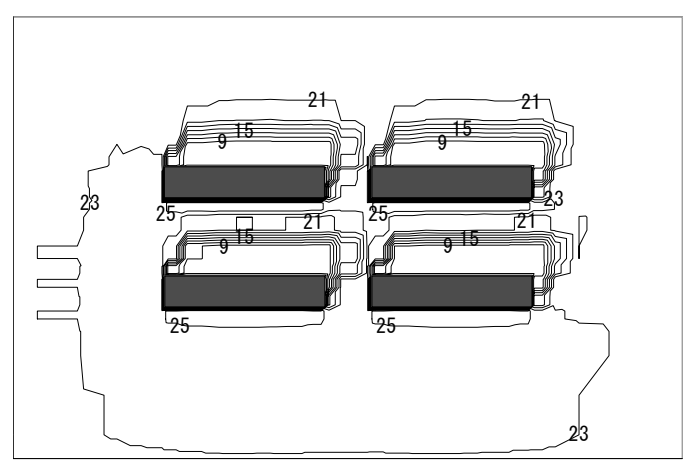

(1) Case 1 (albedo:0.2)

\subsection{Results of Numerical Studies}

(1) Ground Surface Temperature

The ground surface temperatures, $\theta \mathrm{s}$, of Cases 1 and 3 are compared in Fig. 7. Only the values of these two cases are shown here since $\theta$ s for other two cases (Cases 2 and 4 ) are set at $0^{\circ} \mathrm{C}$ as shown in Table 3 . The surface temperature, $\theta$ s, of Case 3 is lower than that of Case 1. The spatial averaged values in the computational domain of Cases 1 and 3 are $17.3^{\circ} \mathrm{C}$ and $7.8^{\circ} \mathrm{C}$ respectively. This is because the albedo of the ground is increased in Case 3 in comparison with Case 1.

\section{(2) Wall Surface Temperature}

Fig. 8 shows the averaged temperature of each wall surface in all cases. The ground temperatures, $\theta \mathrm{s}$, in Cases 2 and 4 are $0^{\circ} \mathrm{C}$, which corresponds to the value of ground surface covered with snow. On the other hand, $\theta \mathrm{s}$ is given from the radiation computation in Cases 1 and 3. Although $\theta \mathrm{s}$ is much lower in Case 4 compared to Case 1, the wall temperatures in Case 4 are generally higher than those in Case 1. This clearly indicates the large effect of an increased albedo caused by the snow in Case 4. In Case 3, $\theta$ s is predicted to be lower in comparison with Case 1, since the value of albedo increases from 0.2, in Case, 1 to 0.8 in this case. However, the wall temperatures in Case 3 become much

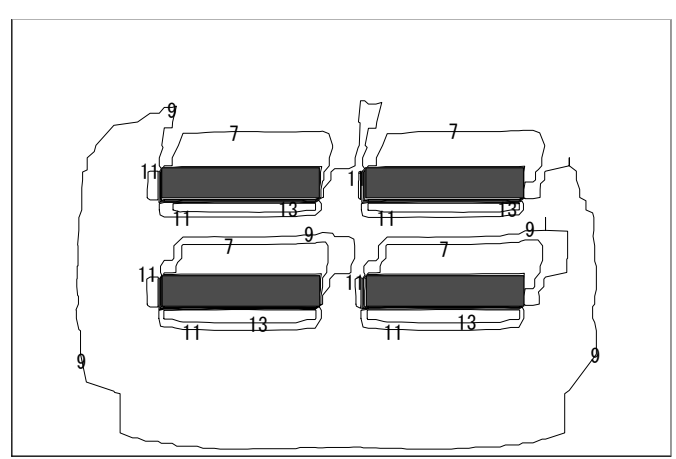

(2) Case3 (albedo:0.8)

Fig.7. Ground surface temperature $\theta \mathrm{s}\left(1: 30\right.$ p.m on February 23 , Nagaoka) $\left({ }^{\circ} \mathrm{C}\right)$

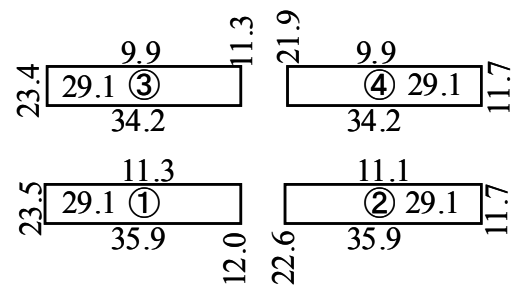

(1) $\operatorname{case} 1$ ( albedo $=0.2, \quad \theta \mathrm{s}=7 \sim 27^{\circ} \mathrm{C}$ )

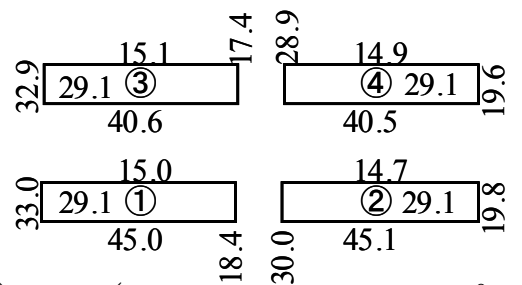

(3) case3 ( albedo=0.8, $\theta \mathrm{s}=5 \sim 15^{\circ} \mathrm{C}$ )

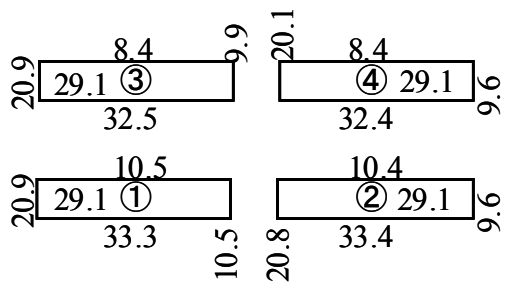

(2) $\operatorname{case} 2\left(\right.$ albedo $\left.=0.2, \quad \theta \mathrm{s}=0^{\circ} \mathrm{C}\right)$
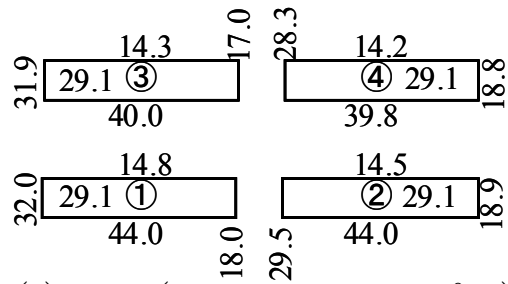

(4) case 4 ( albedo $=0.8, \theta \mathrm{s}=0^{\circ} \mathrm{C}$ )
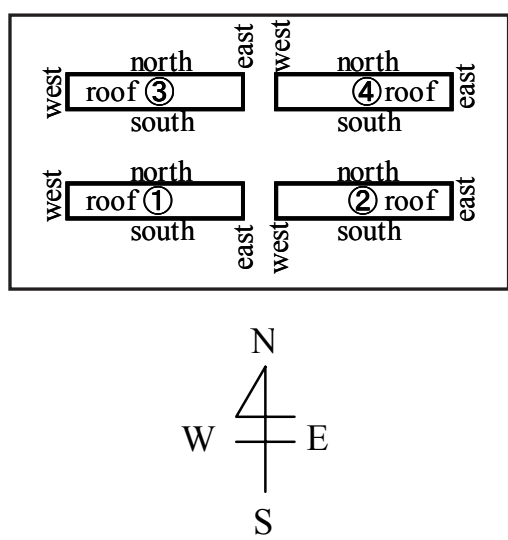

Fig.8. Averaged temperature of wall surface $\left({ }^{\circ} \mathrm{C}\right)$ 


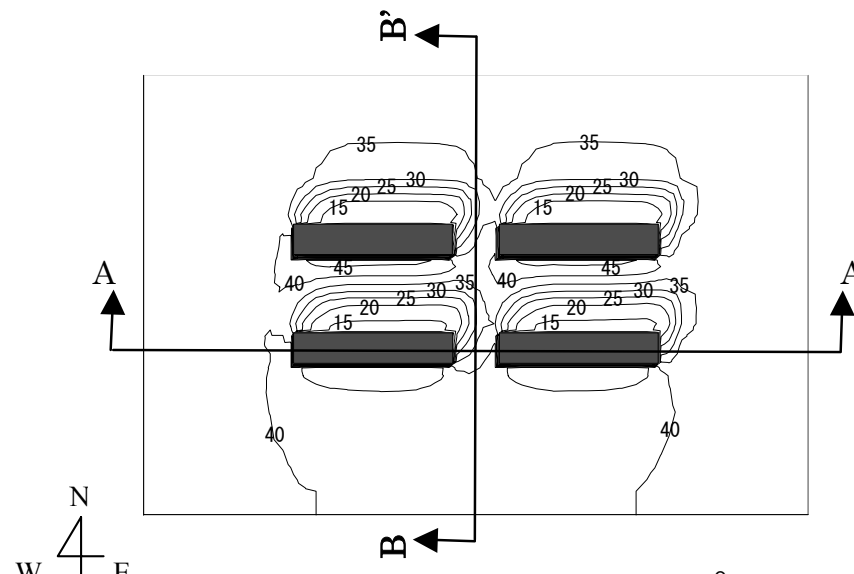

(1) Case 1 (with snow, average: $29.8^{\circ} \mathrm{C}$ )

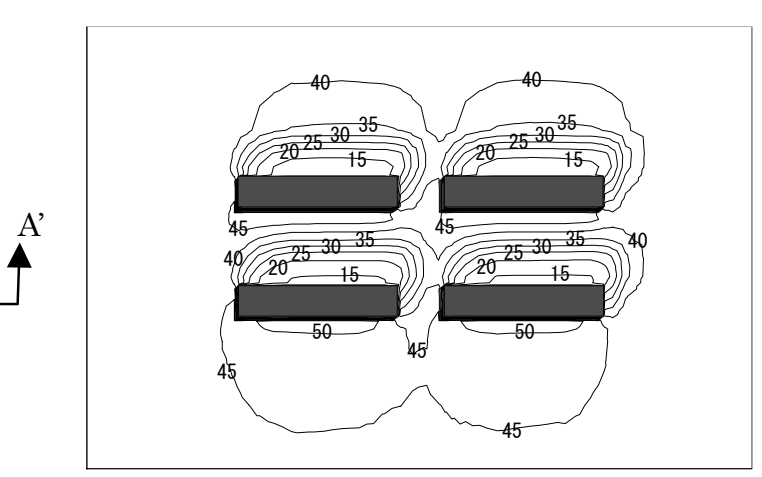

(2) Case 4 (with snow, average: $32.9^{\circ} \mathrm{C}$ )

Fig.9. Horizontal distribution of MRT at $1.5 \mathrm{~m}$ height $\left({ }^{\circ} \mathrm{C}\right)$

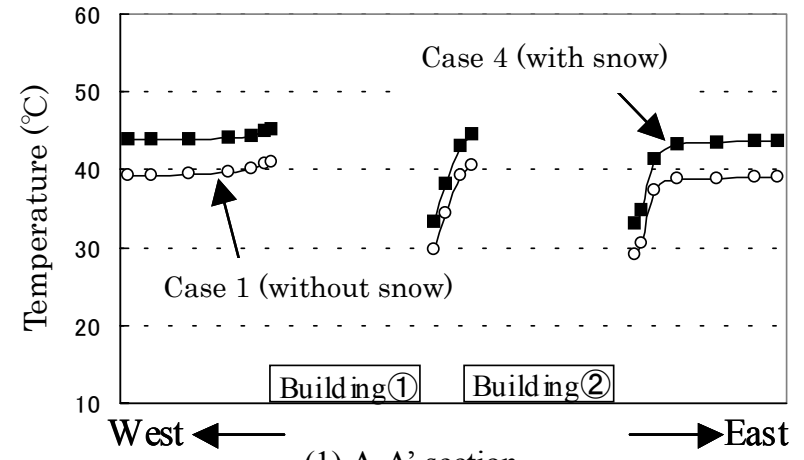

(1) A-A' section

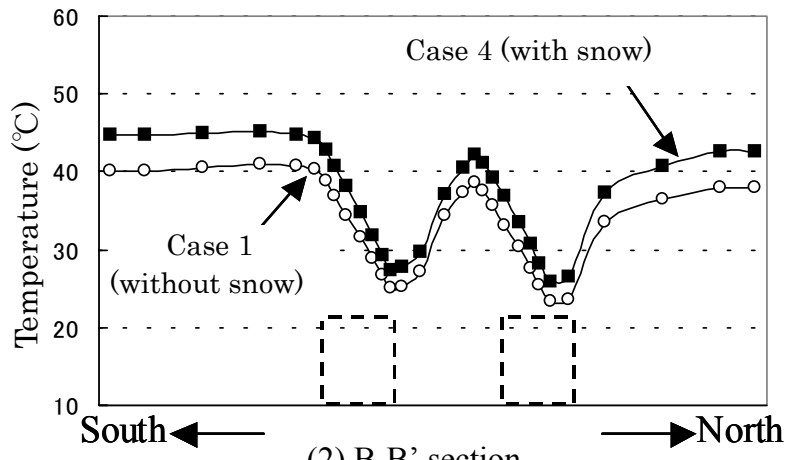

(2) B-B' section

Fig.10. Distributions of MRT at $1.5 \mathrm{~m}$ height $\left({ }^{\circ} \mathrm{C}\right)$

( locations of A-A' and B-B' sections: cf. Fig. 9)

higher than those in Case 1. This difference in the wall temperatures between Cases 1 and 3 also reflects the large effect of the change in the albedo due to snow.

From these results, it can be concluded that the highalbedo has a much stronger effect on the outdoor thermal environment than the low temperature surface that covered with snow does.

\section{(3) Mean Radiative Temperature (MRT)}

Fig. 9 compares the horizontal distributions of MRT at $1.5 \mathrm{~m}$ height in Cases 1 and 4 . The MRT values in Fig. 9 are evaluated from both the long wave and short wave radiations that are absorbed by the human body (Yoshida et al. 2000). The spatial averages of MRT are $29.8^{\circ} \mathrm{C}$ and $32.9^{\circ} \mathrm{C}$ in Case 1 and in Case 4, respectively. The MRT value for Case 4 is generally predicted to be higher than that in Case 1, although the ground surface temperature is much higher in Case $1(7 \sim 27$ $\left.{ }^{\circ} \mathrm{C}\right)$ than that in Case $4\left(0^{\circ} \mathrm{C}\right)(\mathrm{cf}$. Table 3). This is attributable to an increase of reflected solar radiation, due to snow, in a sunny place.

Fig. 10 compares the MRT distributions at A-A' and B-B' sections. The locations of the sections are indicated in Fig. 9. In both cases, the temperature of the nearest wall surface affects the MRT value significantly.
For example, the surface temperature of the west wall of building (2) is about $10^{\circ} \mathrm{C}$ higher than the temperature of the east wall of building (1) (Fig. 8). As a result of this difference in wall temperatures, MRT rises remarkably between buildings (1) and (2) from west to east as shown in Fig. 10(1). On the other hand, MRT decreases in the area near the east wall of building (2), since the surface temperature of the east wall of building (2) is also low. The same tendency is also observed in Fig. 10 (2).

\section{(4) Velocity Vector and Air Temperature}

Fig. 11 illustrates the distributions of the wind velocity vector. Since the differences are relatively small between the four cases conducted in this study, only the result of Case 4 is shown here. As mentioned in 3.1, wind direction at the inflow boundaries (left and bottom sides in Fig. 11 (1)) was set at SSW in this study. However, the direction of the wind is found mainly to flow from the west side into an area that surrounded by the four buildings. A recirculation flow is also observed in this area from the vertical section view (cf. Fig. 11 (2)).

Fig. 12 presents the horizontal distributions of air temperatures at $1.5 \mathrm{~m}$ height for Case 1 (without snow) 


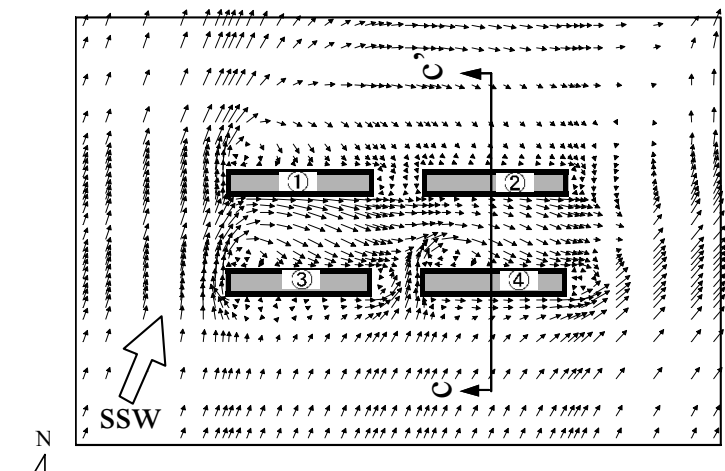

$\mathrm{w}$ 年 (1) Horizontal distribution at $1.5 \mathrm{~m}$ height

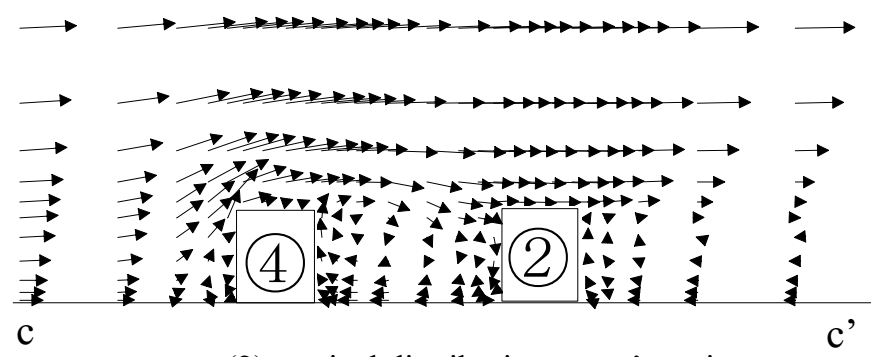

(2) vertical distribution at c-c' section

Fig.11. Velocity vectors of Case 4

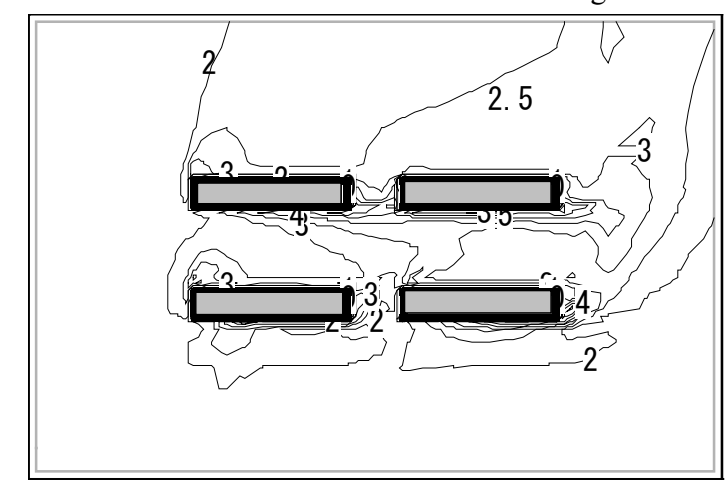

(1) Case 1 (without snow)

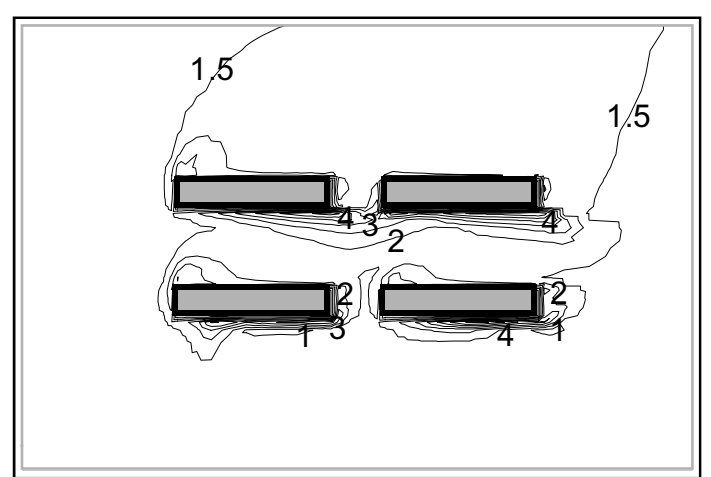

(2) Case 4 (with snow)

Fig.12. Distributions of air temperature at $1.5 \mathrm{~m}$ height $\left({ }^{\circ} \mathrm{C}\right)$

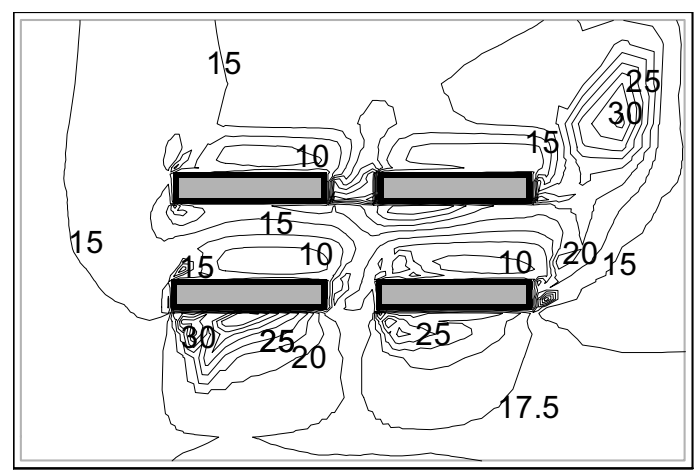

(1) Case 1 (without snow)

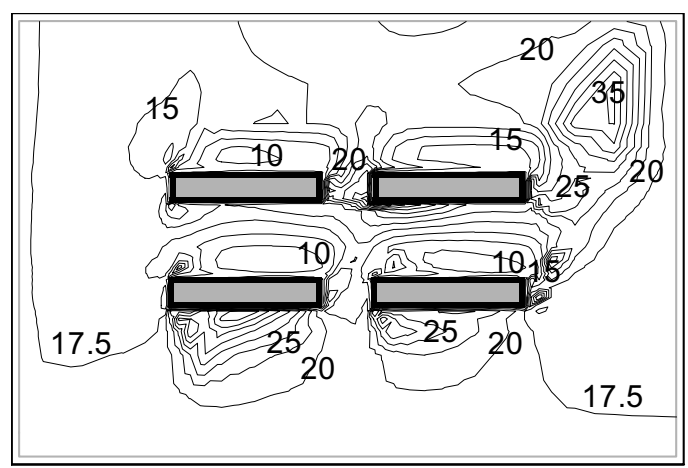

(2) Case 4 (with snow)

Fig.13. Distributions of SET* at $1.5 \mathrm{~m}$ height $\left({ }^{\circ} \mathrm{C}\right)$

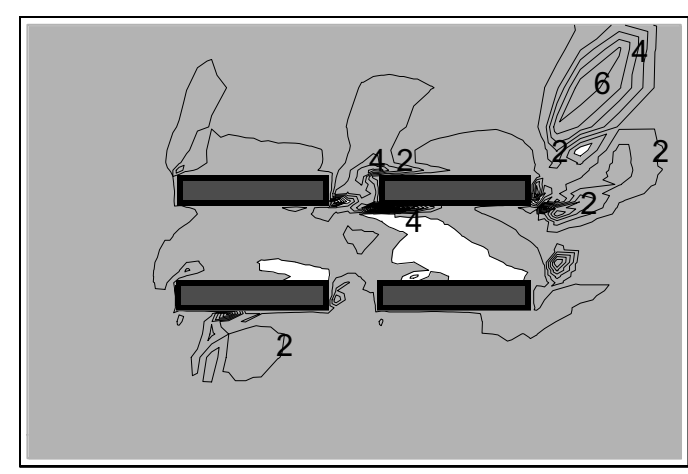

Fig. 14. Difference in SET* at $1.5 \mathrm{~m}$ height $\left({ }^{\circ} \mathrm{C}\right)$ (Case 4 (with snow) - Case 1 (without snow)

- Gray zone indicates the area where SET* in Case 4 (with snow) is higher than that in Case 1 (without snow). and Case 4 (with snow). It is seen, in Fig. 12, that high values of air temperature appear in the areas near the south walls of the buildings in both cases, and the hot air generated from the south walls is convected downstream by the wind flow, shown in Fig. 11. It is also pointed out that the air temperature in Case 1 (without snow) is generally higher than that in Case 4 (with snow) at this height. This reflects the difference in the ground surface temperatures between these two cases (cf. Fig. 7).

\section{(5) $\mathrm{SET}^{*}$}

Fig. 13 compares the predicted SET* of Cases 1 and 4 at the same height (Appendix 4). Fig. 14 shows the difference in $\mathrm{SET}^{*}$ values between the cases with snow (Case 4) and without snow (Case 1), i.e. SET* in Case 4 minus SET* in Case 1 . The gray zone in this figure corresponds to the positive value indicating the area 
where SET* in Case 4 is higher than that in Case 1. The SET $^{*}$ value increases in the case with snow (Case 4) compared to the case without snow (Case 1) almost within the whole domain except for a small area surrounded by the four buildings.

As mentioned above, accumulation of snow decreases the ground surface temperature (Fig. 7) and air temperature (Fig. 12), but increases the wall surface temperature (Fig. 8) and MRT value (Fig. 9). As a result of these effects, it can be concluded that the snow covered surface does not necessarily raise thermal discomfort, but improves outdoor human comfort in sunny weather in winter.

\section{Conclusions}

(1) A numerical method for predicting the radiative and convective heat transports around building blocks in a snowy region was developed. A field measurement was also carried out to clarify the effects of cold and high-albedo surfaces covered with snow.

(2) The MRT value at a height of $1.5 \mathrm{~m}$ above a snow covered surface was found to be $10^{\circ} \mathrm{C}$ higher, at maximum, than the value without snow from the field measurements. This tendency was reproduced well by the numerical method developed in this study.

(3) The effects of cold and high albedo surfaces due to snow on radiative and convective heat transports around buildings were numerically investigated. Although the surface temperature of the ground covered with snow was lower than that without snow, the surface temperatures of the building walls and MRT above the snow surface were predicted to be higher than those without snow, and the increase of MRT caused by snow significantly affects the value of SET*.

(4) The predicated SET* value for the case with snow was higher than that for the case without snow throughout almost the whole domain. This reflects the strong effect of an increased albedo of the ground surface due to the snow.

\section{Acknowledgment}

The authors would like to express their gratitude to Mr. Masaki Hasegawa for his great help within this study.

\section{Appendix 1}

MRT is calculated by the conventional method using the equation (1) based on the measured data

$$
\theta_{r}=\theta_{\text {globe }}+2.37 \sqrt{V}\left(\theta_{\text {globe }}-\theta_{a}\right)
$$

$\theta r:$ MRT value evaluated from globe temperature, $\theta_{\text {globe }}$ : globe temperature,

$\theta_{a}:$ air temperature,

$V^{a}$ : scalar velocity of wind,

$$
V=\sqrt{u_{1}^{2}+u_{2}^{2}+u_{3}^{2}} \text {. }
$$

It should be noted that the application of equation (1) to the environment under the influence of solar radiation may involve some inaccuracy. This point will be
Table 5 The coefficients for radiation computation

\begin{tabular}{|c|c|c|c|}
\hline & $\beta$ & $\alpha$ & $\varepsilon_{\mathrm{s}}$ \\
\hline with snow & 1.0 & 0.75 & 0.95 \\
\hline without snow & 0.3 & 0.15 & 0.95 \\
\hline \multicolumn{4}{|c}{$(\beta \quad$ soil moisture availability $)$}
\end{tabular}

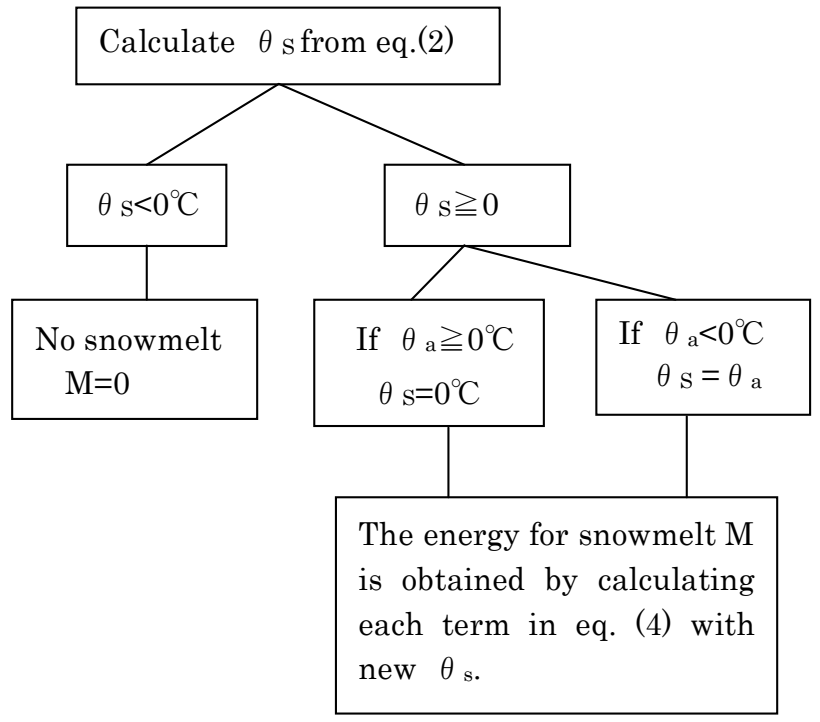

Fig.15. Calculations of snow surface temperature $\theta$ ( $\theta$ s: surface temperature, $\theta$ a: air temperature)

examined further in the near future by the present authors.

\section{Appendix 2}

The heat energy balance at the ground surface on a point $i$ is written as follows (Yoshida et al. (2000)):

$$
\mathrm{S}_{\mathrm{i}}+\mathrm{R}_{\mathrm{i}}+\mathrm{H}_{\mathrm{i}}+\mathrm{C}_{\mathrm{i}}+\mathrm{LE}_{\mathrm{i}}=0
$$

$\mathrm{S}_{\mathrm{i}}$ is the direct and diffuse solar heat gain after multiple reflections. It is calculated using the measured values of global solar radiation $\mathrm{E}_{\mathrm{D}}$ and surface albedo.

$$
S_{i}=A_{i}(1-\alpha) E_{D i}+A_{i} \sum_{j=1}^{n} B_{i j} \alpha E_{D i}
$$

$A_{i}:$ surface area , $B_{i, j}:$ Gebhart's absorption factor,

The set of Gebhart's absorption factors, $\mathrm{B}_{\mathrm{ij}}$, is calculated using the revised Monte Carlo method [Omori et al., (1997)]. $R_{i}$, in equation (2), represents the net long-wave radiation. In this study, the value $\varepsilon s=0.95$ is used for the emissivity at all surfaces [Kondo and Yamazaki, (1986)]. The coefficients employed in the computation of section 2 are summarized in Table 5.

Regarding the snow surface, the energy for snowmelt, M, is added to the right hand side of eq. (2) following Kondo and Yamazaki (1990).

$$
\mathrm{S}_{\mathrm{i}}+\mathrm{R}_{\mathrm{i}}+\mathrm{H}_{\mathrm{i}}+\mathrm{C}_{\mathrm{i}}+\mathrm{LE}_{\mathrm{i}}=\mathrm{M}_{\mathrm{i}}
$$

$\mathrm{M}$ is obtained by substituting $\theta \mathrm{s}$ value, which is determined through the process outlined in Fig. 15, for 
eq. (4). The ground heat flux $C_{i}$ is ignored for the snow surface in this study because it is relatively small (Kondo and Yamazaki, 1986).

\section{Appendix 3}

In this computation, clothing insulation, metabolic heat generation and solar reflectance of the human body are assumed to be 0.6 [clo], 1.0 [met] and 0.5 [-] respectively.

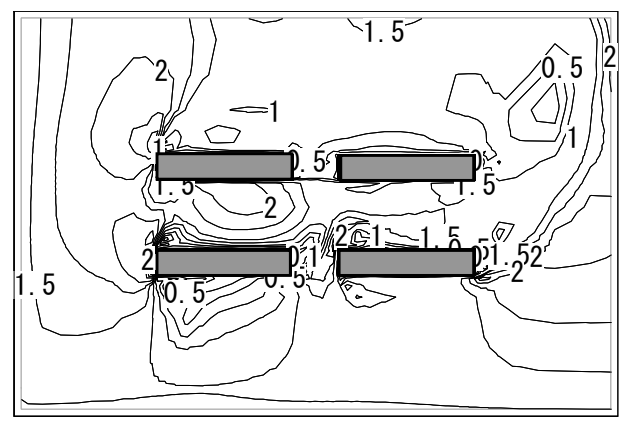

Fig.16. Distributions of wind velocity at $1.5 \mathrm{~m}$ height (Case1 (without snow), m/s)

\section{Appendix 4}

High peaks of SET* are observed in the north-east areas in Figs. 13 (1) and (2). Fig. 16 shows the horizontal distribution of scalar velocity at the same height as in Fig. 13. It can been seen that an area of low wind velocity is formed in the north-east area where SET* shows very high values (cf. Fig.13). Therefore, it can be concluded that this peak of SET* is mainly caused by the decrease of wind velocity in this area.

\section{References}

1) Gagge, A.P., Fobelets A.P. and Berglund, L.G. (1986) A standard predictive index of human response to the thermal environment, ASHRAE Transactions Vol. 92, part 1, 709-731

2) Kato, M and Launder, B. E., (1993) The modeling of turbulent flow around stationary and vibrating square cylinders, 9th Symposium on Turbulent Shear Flows, 10-4-1-6

3) Kondo, J. and Yamazawa, H., (1986) Measurement of snow surface emissivity, Boundary Layer Meteorology, vol. 34, 415416

4) Kondo, J. and Yamazaki, T. (1987) Estimates of snowmelt by a heat balance method, Seppyo, vol. 49, No. 4, 181-191 (in Japanese).

5) Kondo, J. and Yamazaki, T., (1990) A Prediction model for snowmelt, snow surface temperature and freezing depth using a heat balance method, Journal of Applied Meteorology, vol. 29 , 375-384

6) Launder, B. E. and Spalding, D. B., (1974) The numerical computation of turbulent flows, Comp. Meth. Appl. Meck. Eng. 3, 269-289

7) Murakami, S., Ooka, R., Mochida, A., Yoshida, S., Kim, S. (1999) CFD analysis of wind climate from human scale to urban scale, Journal of Wind Engineering and Industrial Aerodynamics, 81, 57-81

8) Omori, T., Murakami, S. and Kato, S. (1997) Numerical Simulation of Solar Heat Absorption within Indoor Space by Means of Composite Grid Method, ASHRAE Transactions, vol. 103, Pt.7.

9) Yoshida, S., Murakami, S., Mochida, A., Ooka, R., Tominaga, Y. and Kim, S. (2000) Influence of Green area ratio on outdoor thermal environment with coupled simulation of convection, radiation and moisture transport, J. Archit. Plann. Environ. Eng., AIJ, No. 529, 77-84 (in Japanese).

\section{Notation}

$\langle f\rangle$ : time-averaged value of $f$

$f^{\prime}:$ deviation from $\langle f\rangle, f^{\prime}=f-\langle f\rangle$

$x_{\mathrm{i}}$ : three components of spatial coordinate

( $x_{1}$ : east-west direction, $x_{2}$ : north-south direction, $x_{3}$ : vertical direction)

$u_{\mathrm{i}}:$ three components of velocity vector

$\theta_{a}:$ air temperature

$\theta_{s}:$ ground surface temperature

$\theta_{\text {globe }}$ : globe temperature

MRT : Mean radiative temperature

$\theta_{r} \quad$ : MRT value evaluated from $\theta_{\text {globe }}$ (cf. eq. (1))

qw : absolute humidity

$\mathrm{k}$ : turbulent kinetic energy

$\mathcal{E}$ : dissipation rate of $\mathrm{k}$ 